\title{
Letter to the Editors
}

The volume is well illustrated, and a striking portrait of Lord Lister as President of the Royal Society forms an admirable frontispiece.

The late Sir Norman Moore's learned address, delivered in I9I3 at the opening of the Wellcome Historical Medical Museum, is published as an appendix. A. Logan TURner.

\section{LETTER TO THE EDITORS.}

THE "SCLEROTIC" MASTOID PROCESS.

The Editors,

Journal of Laryngology and Otology.

Dear Sirs,--The "Sclerotic" type of mastoid process to which Dr MacGibbon referred in the August number is very rare and is seen in about $\mathrm{I}$ per cent. of bones.

The acellular type, of which $I$ send an illustration, is fairly common, and $I$ have said that it is responsible for middle-ear suppuration becoming chronic.

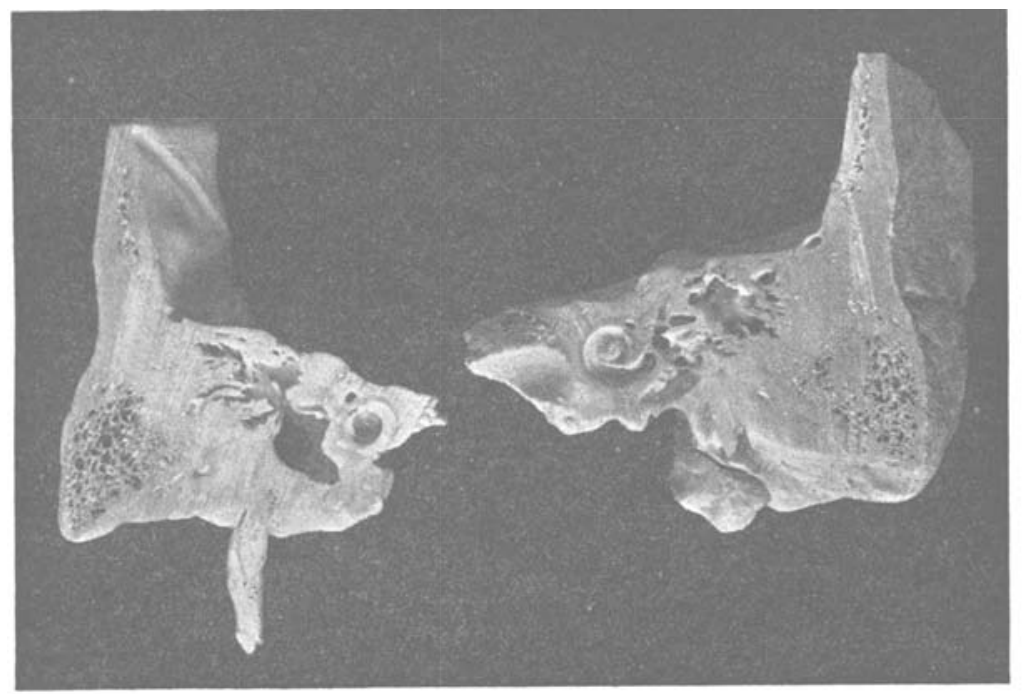

In May I908, I first described this type of bone, and I see that Professor Mouret and Professor Wittmaack are going to discuss the subject next year at the International Congress in Copenhagen.-Yours faithfully, Arthur H. Cheatle.

London, August I927. 